\title{
Natural disasters and labor markets
}

\author{
Martina KIRCHBERGER ${ }^{a *}$ \\ a Centre for the Study of African Economies, \\ Department of Economics, University of Oxford
}

\begin{abstract}
:
While it is clear that natural disasters have serious welfare consequences for affected populations, less is known with respect to how local labor markets in low income countries adjust to such large shocks, in particular the general equilibrium effects of the increase in the demand for construction as well as the inflow of resources in the aftermath of natural disasters. Building on the literature on local labor markets (Moretti, 2010a,b), this paper investigates whether there is evidence that changes in the relative prices of non-tradable to tradable goods induced by a demand shock due to a natural disaster lead to a reallocation of employment and wage premia across sectors. Combining data from the Indonesia Family Life Survey and the US Geological Survey we study the effect of earthquakes on local labor markets in Indonesia. We find evidence for sectoral reallocation of workers as well as significant and persistent wage premia. Employment in the construction sector increases significantly and contracts in the agriculture sector in the two years after an earthquake takes place in a community. There appear to be substantial labor market rigidities since even after sectoral mobility has taken place, individuals employed in sectors producing non-tradable goods experience significantly higher wage growth in communities that were struck by an earthquake. These effects are homogenous along the quantiles of the conditional income growth distribution. Thereby, they neutralize otherwise occurring differential earnings growth patterns across sectors and operate as pure location shifts of the income distribution rather than altering the shape.
\end{abstract}

Keywords: local labor markets, natural disasters, Dutch disease JEL classification: J20, Q54, O10

${ }^{*}$ Correspondence: Centre for the Study of African Economies (CSAE), Department of Economics, Manor Road Building, Oxford OX1 3UQ, UK; Email: martina.kirchberger@economics.ox.ac.uk 


\section{Introduction}

Despite the total number of natural disasters being roughly equal for high and low income countries, their impact in terms of fatalities has been found to be substantially higher in low income countries (Stromberg, 2007). About 99\% of people affected by natural disasters over the period of 1970-2008 reside in the Asia-Pacific region, Latin America and the Caribbean or Africa, accounting only for $75 \%$ of the world population (Cavallo and Noy, 2009). It is clear that there are vast welfare and asset losses associated with natural disasters which often, and luckily so, are followed by large inflows of resources for emergency relief and reconstruction. In many cases, the housing sector accounts for a significant proportion of total damage and losses: for example, $40 \%$ of the damage and losses from the 2010 earthquake in Haiti is due to destroyed and damaged housing (Government of Haiti et al, 2010). This figure is even higher for the 2009 West Sumatra earthquake (BNPB et al, 2009) and about half for the 2006 earthquake in Yogyakarta and Central Java (BAPPENAS, 2006). Once the emergency phase is over, aid flows often last for several years following the disaster.

Figure 1: Post Tsunami Fund Allocations by Sector, Aceh, Indonesia
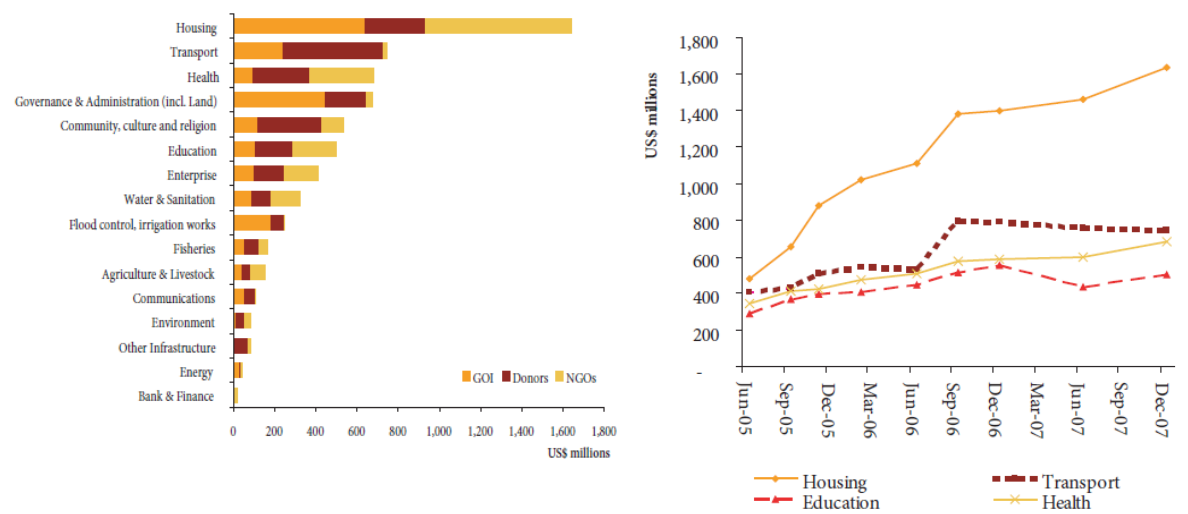

Source: World Bank (2008).

Figure 1 shows that post-tsunami allocations to the housing sector in Aceh in Indonesia amount to $\$$ US 1.6 billion, which is equivalent to $25 \%$ of total reconstruction funding and $30 \%$ of Aceh's regional GDP. As the panel on the right shows, resource flows can last over several years.

However, we know little with respect to how local labor markets in low and middle income countries adjust to large destructive shocks such as earthquakes and hurricanes, in particular how flexible labor markets are to accommodate such large demand shocks due to the increase in the demand for construction as well as the inflow of resources in the aftermath of natural disasters.

A substantial body of literature in development economics explores how shocks impact on households along a number of dimensions, including households' ability 
to smooth consumption, ex-ante and ex-post coping strategies as well as short and long-term effects of shocks on a range of outcomes such as consumption, schooling, health and child work (Townsend, 1994; Paxson, 1992; Udry, 1995; Dercon, 2004). Employment in the non-agricultural sector has been found to be an important strategy for agricultural households to diversify their portfolio ex-ante as well as ex-post (Rose, 2001; Kochar, 1999; Takasaki, Barham, and Coomes, 2010; Cameron and Worswick, 2003). A few studies investigate the impact of weather shocks (droughts, floods) on labor markets, and they focus either entirely on the agricultural labor market or only distinguish between agricultural vs non-agricultural workers, rural vs urban wages or livelihood strategies but not between employment sectors (Jayachandran, 2006; Mueller and Osgood, 2009; Mueller and Quisumbing, 2010; Banerjee, 2007; Van den Berg, 2010).

This paper investigates whether there is evidence for general equilibrium effects through changes in the relative price of non-tradable to tradable goods, such as a reallocation of employment and wage premia between sectors producing tradable vs non-tradable goods. We find evidence of sectoral reallocation of workers as well as significant and long lasting wage premia for individuals employed in sectors producing non-tradables. The proportion of individuals employed in agriculture increases by $2.7 \%$ and $5.9 \%$ points in the first and second year, respectively, following an earthquake. This is accompanied by a contraction in the agriculture sector, where employment is reduced by $4.1 \%$ points one year after the earthquake and by $9.1 \%$ points two years after the earthquake took place. There appear to be substantial labor market rigidities since even after sectoral mobility has taken place, individuals employed in sectors producing non-tradable goods enjoy significantly higher wage growth. Individuals employed in the construction and service sector in a community that was hit by an earthquake experienced about $60-100 \%$ and about $30-40 \%$, respectively, higher earnings growth between 2000 and 2007 compared to individuals employed in agriculture. These effects are fairly homogenous along the quantiles of the conditional income growth distribution. Thereby, they neutralize otherwise arising differential earnings growth patterns across sectors and operate as pure location shifts of the income distribution rather than altering the shape.

The paper is structured as follows. Section 2 presents some evidence from related studies; section 3 provides a conceptual framework to outline the channels through which natural disasters might impact on local labor markets; sections 4 and 5 describe the Indonesian context and the data. The econometric framework is presented in section 6 and section 7 discusses the results. Section 8 concludes.

\section{Literature}

The existing evidence on how natural disasters work through economies, in particular labor markets, is scarce. We start by presenting some findings from the macro liter- 
ature on the effects of natural disasters on GDP and GDP growth; we then review evidence from the micro literature on the impact of natural disasters on outcomes such as poverty and migration where we focus on destructive natural disasters. As there is little evidence on the effect of destructive natural disasters on labor markets, in addition to destructive natural disasters, we also include studies that investigate the impact of weather shocks on wages and labor markets in low and middle income countries. Finally, we discuss insights from the labor economics literature on the impact of demand side shocks on sectoral labor market dynamics and the existence of local multipliers.

There is an ongoing debate in macroeconomics on whether natural disasters harm economic growth, foster it, have impacts only under certain conditions, or no impact at all. For example, Hochrainer (2009) finds that natural disasters have significant negative effects on GDP in the medium run; higher aid rates and higher remittances lessen the adverse effects and higher capital stock losses worsen the negative effects. Noy (2009) finds stronger negative effects of natural disasters for developing countries and smaller economies compared to developed or bigger economies. On the other hand, Skidmore and Toya (2002) find a positive correlation between the frequency of climatic disasters and growth in total factor productivity and GDP. Cuaresma, Hlouskova, and Obersteiner (2008) argue that 'creative destruction' and technology upgrading in the aftermath of disasters can take place, but only at high levels of economic development. Finally, Loayza, Olaberría, Rigolini, and Christiaensen (2009) find that the effect of natural disasters is heterogenous with regard to the type and severity of a natural disaster and the level of development of a country; further, they find evidence for significant differences in impacts by sector. Examining the effect of hurricanes in the US on local growth rates, Strobl (2010) finds that hurricanes significantly reduce county-level growth rates but the effect is fairly short-lived and disappears one year after the earthquake.

Several studies look at the impact of natural disasters on poverty, and a few studies on migration. Baez and Santos (2008) investigate the impact of two earthquakes in El Salvador that struck in early 2001. They use the last two rounds of the BASIS El Salvador Rural Household Survey and find that household income per capita is reduced by one third for households in the upper half of the shaking distribution; although not statistically significant, severity and depth of poverty increases. Premand (2008) estimates micro growth models using data from the Nicaraguan LSMS, focusing on agricultural households, and finds moderate short term effects of hurricane Mitch on consumption growth but no evidence for persistence. Halliday (2006) investigates the impact of harvest and livestock loss as well as two earthquakes on the probability of sending a migrant to the United States as a coping strategy in the aftermath of a disaster. He finds that earthquakes reduce the likelihood of sending a migrant to the U.S. across all wealth levels. From this he concludes that it is not due to liquidity constraints that households don't send a migrant in response to an 
earthquake shock but rather through the need for the migrant at home. While he observes an increase in remittances following harvest and livestock loss, remittances tend to be lower after earthquakes. Yang (2008) on the other hand, using the same data for El Salvador, argues that the decrease in migration following an earthquake is due to liquidity constraints. Datt and Hoogeveen (2003) use data from the Philippines to evaluate the impact of a (i) labor market shock alone due to the Asian Crisis; (ii) El Niño shock (drought) alone and (iii) joint labor market and El Niño shock on consumption and income. They find that largest share of the overall impact on poverty is attributed to the El Niño shock as opposed to the labor market shock.

A few studies investigate the link between extreme weather events such as floods, droughts or hurricanes on wages and employment. Jayachandran (2006) indirectly examines the relationship between wages and weather shocks in the agricultural labor market, instrumenting yields with rainfall shocks in a regression of agricultural wages on yields, variables influencing the elasticity of labor supply and other covariates. Using data from a panel of 257 districts in India, she finds that agricultural wages respond more to productivity shocks in the absence of financial institutions and migration opportunities, factors that would make labor supply more elastic. Estimating a similar reduced form model for Brazil, Mueller and Osgood (2009) find negative wage effects of droughts on rural wages that last up to five years.

Mueller and Quisumbing (2010) use data from the Bangladesh Flood impact panel household survey to evaluate the impact of the 1998 flood. They find short time wage losses for agricultural workers and long-term wage losses for nonagricultural workers; short term drops in wages are sharper for communities that are located further away from markets but distance to a market is then positively correlated with wages in the long term. Banerjee (2007) also looks at the impact of floods in Bangladesh on wages of male agriculture workers and finds negative effects if floods occur in the dry harvest season but positive effects if the floods occur during the growing period of wet-season crops.

Belasen and Polachek $(2008,2009)$ investigate the labor market consequences of hurricanes in Florida, exploiting differences in county-level earnings and employment rates calculated from quarterly data. Employing a Generalized Difference in Difference technique, they find a positive earnings effect and a negative employment effect for counties struck by a hurricane while neighboring counties experience a negative earnings effect but no employment effect. Analyzing sectoral composition, they find that earnings and employment effects move together for both directly affected and neighboring counties, with positive effects on wages and employment in the construction and service sector for directly affected counties ${ }^{1}$.

A related literature focuses on general equilibrium effects of demand shocks in local labor markets with evidence mainly from developed countries. Moretti (2010b)

\footnotetext{
${ }^{1}$ Some studies use hurricanes as natural experiments to investigate the impact of migration on receiving labor markets, for example see McIntosh (2008); Silva, McComb, Moh, Schiller, and Vargas (2010).
} 
uses data from the US Census of Population and finds a significant relationship between changes in the number of jobs in a city in the tradable sector and the nontradable sector. Each additional job in the tradable sector is associated with 1.6 jobs created in the non-tradable sector in a city or 2.5 additional jobs in the non-tradable sector if the additional job in the tradable sector is taken up by a worker with some college education or more. Carrington (1996) finds a significant short run employment multiplier from the construction of the Trans-Alaskan Pipeline System in other parts of the economy. Kline (2008) uses data for the US oil and gas field services industry and investigates labor market responses to changes in the price of crude petroleum. He finds that the labor market quickly reallocates across sectors in response to price changes, but substantial wage premia are necessary to induce the reallocation. Wage premia emerge quite slowly and peak only as labor adjustment ends and then slowly dissipate.

\section{Conceptual Framework}

This section sets out a simple framework outlining the effects a natural disaster can have on local labor markets. It combines approaches from the labor economics literature on local labor markets (Moretti, 2010a,b), work on sectoral labor market dynamics (Carrington, 1996; Keane and Prasad, 1996; Kline, 2008) and the predominantly macro-focused literature on Dutch-disease type of effects (Corden and Neary, 1982; Corden, 1984; Collier and Gunning, 1999).

Assume a small open economy consisting of $\mathrm{J}$ communities. There are 2 types of goods, tradable $(T)$ and non-tradable goods $(N T)$, which are produced in 4 sectors: agriculture $(A)$, construction $(C)$, manufacturing $(M)$ and services $(S)$. Tradable goods are produced by firms in the agriculture or manufacturing sector so that $x^{T}=$ $\left\{x_{A}^{T}, x_{M}^{T}\right\}$, using labor and a sector specific factor as inputs. The supply of tradables is perfectly elastic and they are traded at national prices $p^{T}=p$ so that firms are price takers and have zero profits. Firms producing tradables can freely enter and exit labor markets in the $\mathrm{J}$ communities. Non-tradable goods are produced by local firms in the construction or services sector $x^{N T}=\left\{x_{C}^{N T}, x_{S}^{N T}\right\}$; firms producing non-tradables maximize profits using labor and a sector specific factor as inputs to production. Non-tradable goods are priced at $p^{N T}$ which is determined by the intersection of local supply and local demand; firms can enter and exit the construction or services sector and expand and contract facing adjustment costs. Thus, supply is inelastic in the short run but elastic in the long run.

Each community $\mathrm{j}$ has a local labor market with a labor force of size $n^{j}$ that is homogenous in skills. Labor supply is upward sloping and workers are paid their marginal product. Individuals are employed in one of the four sectors where the total labor force in community $\mathrm{j}$ is equal to the sum of workers in each sector. Workers are allocated to a sector randomly at the beginning of their career. They face adjustment 
costs for moving between sectors which reflect the initial training period required to obtain the sector-specific set of skills. If the expected utility from moving from one sector to another (which depends on the sectoral wage premium offered and adjustment costs) exceeds the expected utility from remaining in the current sector, they switch between sectors. Each worker provides one unit of labor and receives a sector specific wage. Individuals maximize utility derived from consuming their optimal bundle of goods produced in the four sectors subject to a budget constraint that is composed of wage income plus non-labor income.

We now consider the effect of a destructive natural disaster on the local labor market. Assume that the natural disaster is a rapid-onset event such as a hurricane or an earthquake which has an immediate effect that wears off fairly quickly ${ }^{2}$. Neither firms nor workers can predict the event. Therefore, firms can not ex ante expand or contract or change their capital-labor ratios in order to reduce adjustment costs once the disaster strikes. The disaster leads to destruction of physical assets such as private and public buildings as well as infrastructure such as roads and bridges ${ }^{3}$. It is followed by an inflow of external resources earmarked for reconstruction of destroyed buildings ${ }^{4}$.

\section{$3.1 \quad$ Non-tradables}

The increased demand for construction leads to an increase in the demand for labor in the construction sector ${ }^{5}$; to accommodate a movement of labor the wage in the construction sector has to increase. In response to this wage premium workers for which the expected utility from moving sectors exceeds the expected utility from staying in their current sector shift into the construction sector until the sectoral wage premium is driven to zero ${ }^{6}$. The speed at which this adjustment takes place depends on how elastic labor supply is with respect to wages and how mobile workers are across sectors (interindustry elasticity of labor supply). As the construction sector expands there are general equilibrium effects on employment in the service sector (the second non-tradable sector) as well as the agriculture and manufacturing sectors, the 2 sectors producing tradables.

The demand for services increases due to two factors: (i) the increased size of the construction sector leads to an increase in the demand for intermediate goods

\footnotetext{
${ }^{2}$ The opposite is what the disaster literature refers to as 'slow-onset disasters' such as a drought (Benson and Clay, 2004). Potential behavioral responses by individuals and governments are very different for these two types of disasters.

${ }^{3}$ As documented in the Introduction, the housing sector is particularly affected by natural disasters. For the moment we only assume physical asset loss; if human loss is factored in as well, there would be a further downward shift of the labor supply schedule.

${ }^{4}$ So far we abstract from the increased demand for services for the provision of relief services in the immediate aftermath of an earthquake and focus on the increased demand for construction. Including this additional increase in demand for services would leave the narrative unchanged, there would simply be a stronger increase in the demand for services.

${ }^{5}$ Corden (1984) calls this the 'spending effect'.

${ }^{6}$ Corden (1984) calls this the 'resource movement effect'.
} 
produced both in the service and manufacturing sector. As services are supplied locally and supply is inelastic in the short run, this leads to an increase in the wage premium paid in the service sector to accommodate the expansion of the sector; (ii) the increase in wages of individuals employed in the production of non-tradables leads to an increase in the demand for local services (provided that the income elasticity of demand for services is positive, the size of the effect depends on consumers' preferences over tradables and non-tradables); similar to the construction sector, wages in the sectors producing non-tradables increase until the wage premium has been driven to zero. Therefore, the increase the ratio of $p^{N T} / p^{T}$ draws workers out of the tradable sector into the non-tradable sector.

\subsection{Tradables}

As a consequence, the higher price level of local inputs into production leads to a decrease in the relative competitiveness of firms producing tradable goods as they have to compete with firms that are potentially able to produce at lower costs in other communities. In response, firms might downsize or relocate to unaffected communities and the tradable sector contracts. How strong the contraction is depends on two factors. First, on the tradability of inputs required for construction activities that are produced in the manufacturing sector, such as equipment and machinery. The more tradable inputs are the stronger the contraction as construction firms in the affected community can purchase inputs from other communities where firms produce manufactured goods at lower prices. Second, the effect on firms in the manufacturing and agriculture sector depends on individuals' preferences over tradable versus nontradable goods. The lower individuals' income elasticity of demand for non-tradable goods the stronger the change in the relative prices and the more firms producing tradable goods are going to contract.

In summary we would expect to observe the following effects in communities that are struck by a natural disaster:

- An expansion of employment in the non-tradables sector and a contraction in the tradables sector

- A wage premium for workers employed in non-tradable sectors in the aftermath of an earthquake that then disappears.

A number of issues have not been considered in the framework so far. For example, the role of destruction of firm's capital stock by the natural disaster. If the natural disaster raises firm owners' expectations over the occurrence of another natural disasters in the future, this might lower the expected return to physical capital and raise the expected return to human capital, leading to a change in the firm's optimal capital-labor ratio. Further issues include agglomeration effects that might arise due to the increase in production in the construction sector, the role of access 
to credit in facilitating the expansion of firms producing non-tradables, the difficulty in adjusting capital labor ratios particularly in the construction sector, and the role of heterogeneity in skills. There might be important composition effects if the additional workers required in the non-tradables sector are from either the higher or lower end of the skill distribution which in turn might change individuals' return to education and consequently their decision on how much to invest in their human capital. Additionally, increases in the demand for non-tradables could be higher if new jobs in sectors producing non-tradables are occupied by more-skilled, higher earning individuals provided that the income elasticity of demand for non-tradable goods is positive.

\section{Context}

To investigate the effect of natural disasters on local labor markets, we use data for earthquakes in Indonesia, one of the seismologically most active regions worldwide which makes it a suitable country to study the question at hand. More than 10 million people have been affected by an earthquake or a flood in the past 10 years. Indonesia is located on the boundary between the Sunda plate in the North-East and the Australia plate in the South-West. The Australia Plate is moving $50-60 \mathrm{~mm}$ per year northward with respect to the Sunda plate in the South-East and 40-50 mm per year northward in the North-West (US Geological Survey, 2008). Inter-plate earthquakes (caused by the subduction of the Australia plate beneath the Sunda plate) and intra-plate earthquakes (caused by stresses generated in the subduction process) are occurring frequently.

Figure 2 shows earthquakes with a magnitude larger than 5 on the Richter scale in the region from the beginning of 1988 until February 2008. Colored circles indicate earthquakes with a magnitude of at least 7.7 and aftershocks within the following 31 days. The green symbol denotes earthquakes for which fatalities were listed in the Preliminary Determination of Epicenters publication of the U.S. Geological Survey. From this map it is clear that earthquakes can happen anywhere in Sumatra and Java and can thus be treated as random, therefore, it is not possible to predict a priori where the next earthquake is going to happen.

\section{Data}

We combine two sources of data. First, we use household and community level data from the Indonesia Family Life survey, a large-scale panel household survey conducted in 1993, 1997, 2000 and 2007. In this study we only use data for males aged 1565 and for the last two rounds, since the retrospective disaster module was only collected in the 2007 round, and further, including the previous years would make it far more difficult to disentangle the effect of natural disasters from the effects of the 
Figure 2: Western Indonesia Earthquakes, 1988 - February 2008

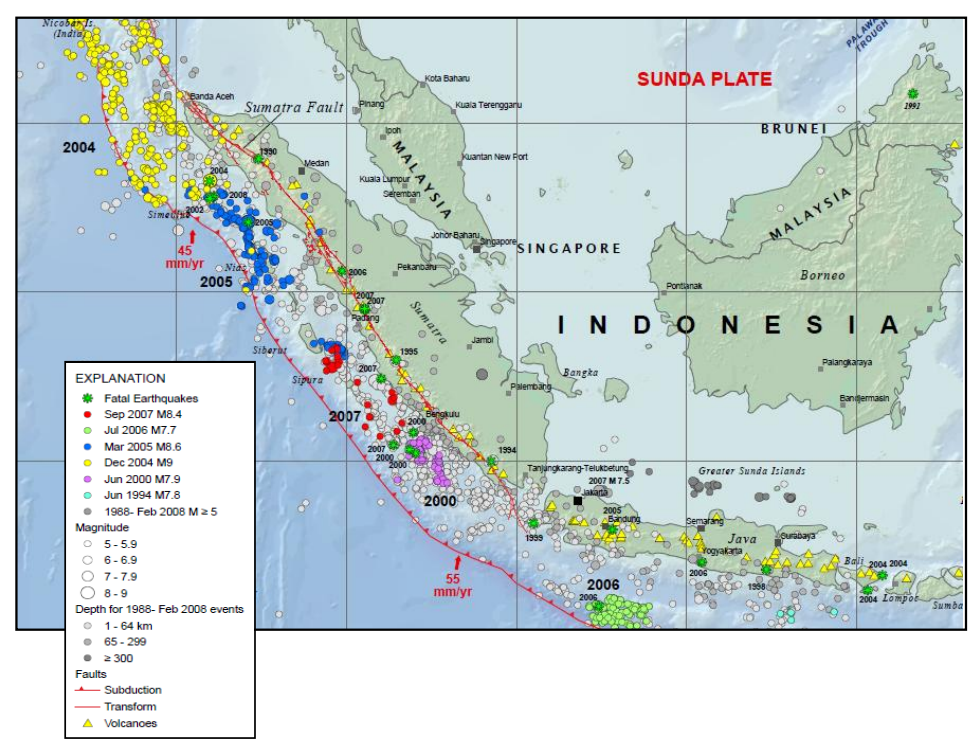

Source: US Geological Survey (2008).

financial crisis and the contemporaneous El Nino shock. The initial sample includes 321 communities and is representative of $83 \%$ of the Indonesian population living in 13 of the country's 26 provinces. Second, the National Earthquake Information Center, a part of the Department of the Interior, U.S. Geological Survey, collects detailed information on the epicenter, magnitude and depth of earthquakes worldwide since 1973 until the present. Using Vincenti's formula (Vincenty, 1975) we spatially link the clusters and the epicenter of the earthquakes. A community is recorded as having suffered from an earthquake if an earthquake with more than a magnitude of 5 on the Richter scale hit a community and with a distance of less than $35 \mathrm{~km}$ distance during the five years before the survey.

To investigate whether there are sector-specific shifts in the demand for labor we use the retrospective employment history collected in 2007 which contains information on the sector individuals were employed in during the 9 years prior to the survey. Based on this information we construct a community level panel and calculate the proportion of individuals employed in a certain sector in each community. We then merge this community level panel with the community level shock history from which the most recent earthquake is known.

Income reported for a respondent's primary job forms the basis for computing hourly wages. Income for privately employed individuals is measured as last month's salary including the value of all benefits. Monthly salary is replaced by yearly salary divided by 12 for cases in which only the latter was reported. For self-employed individuals, wage data are derived by subtracting business expenses from net profits. In IFLS 3, self-employed respondents who did not know their net profit gained in the 
last month were further asked for their gross income gained during the last month. Although this would allow us to get income data for these individuals, as this question is dropped in IFLS 4, for comparability we drop observations who reported zero profit in either of the rounds.

Following (Strauss, Beegle, Dwiyanto, Herawati, Pattinasarany, Satriawan, Sikoki, Sukamdi, and Witoelar, 2004), we compute hourly wages on the basis of monthly reported earnings divided by the total hours worked last week multiplied by 4.33. We top code individuals who reported working more than a total of 126 hours per week to 126 (assuming a maximum work load of 18 hours per day for 7 days a week) and only include individuals with positive earnings in both years ${ }^{7}$.

Following Thomas, Frankenberg, and Teruel (1999), we deflate 2007 and 2000 wages to the base year 1996 using a province-specific price deflator that is based on the BPS price indices reported for 45 cities in Indonesia (43 cities until 2003), matching the BPS cities to the IFLS provinces and using a simple average of the price indices for provinces with more than one city ${ }^{8}$.

Table 1: Summary statistics

\begin{tabular}{lccc}
\hline \multicolumn{1}{c}{ Variable } & Mean & Std. Dev. & N \\
\hline Age & 36.829 & 10.876 & 2770 \\
Primary Education & 0.456 & 0.498 & 2770 \\
Secondary Education & 0.403 & 0.491 & 2770 \\
Tertiary Education & 0.094 & 0.292 & 2770 \\
Urban & 0.536 & 0.499 & 2770 \\
Earthquake & 0.054 & 0.226 & 2770 \\
Earthquake Community & 0.201 & 0.401 & 2770 \\
Agriculture & 0.271 & 0.445 & 2770 \\
Construction & 0.161 & 0.368 & 2770 \\
Manufacturing & 0.098 & 0.297 & 2770 \\
Services & 0.47 & 0.499 & 2770 \\
\hline
\end{tabular}

Table 1 presents some basic descriptive statistics of the sample in 2007. The average age is almost 37 years. $46 \%$ of the respondents have primary education, and about $40 \%$ have secondary education. About $9 \%$ has tertiary education. Slightly more than half of the sample lives in urban communities. $5.4 \%$ of individuals reports an earthquake in the area in which they live that was 'severe enough to cause death or major injuries of a household member, direct financial loss to the household, or cause household members to relocate'. About $20 \%$ of the communities report an earthquake. With regards to employment, $27 \%$ of individuals are employed in agriculture, $16 \%$ in construction, $9 \%$ in manufacturing and $47 \%$ in services.

\footnotetext{
${ }^{7}$ Strauss, Beegle, Dwiyanto, Herawati, Pattinasarany, Satriawan, Sikoki, Sukamdi, and Witoelar (2004) bottom code individuals with zero wage to rp30/hour.

${ }^{8}$ Thomas, Frankenberg, and Teruel (1999) construct an alternative measure for inflation based on the price data collected in the IFLS community questionnaire and find that rural inflation was $5 \%$ higher than urban inflation; therefore, they decide to further inflate prices for rural residents. Given that the period between 2000 and 2007 has noted a far more stable price environment than pre-crisis, we only use the BPS price data. As will be explicit in the next section which outlines the empirical framework, we take first differences to account for location specific time invariant effects; further, we include a dummy variable if the household lives in an urban area as well as community fixed effects to allow for differential wage growth in urban centers and for each of the communities.
} 
As discussed in the conceptual framework, we would expect different rates of wage growth in tradable and non-tradable sectors affected by the demand and supply responses to natural disasters only if labor markets are not flexible enough to adjust to the differential in sectoral wage premia.

Figure 3: Univariate Parzen estimator of changes in log of earnings between 2000 and 2007

Agriculture

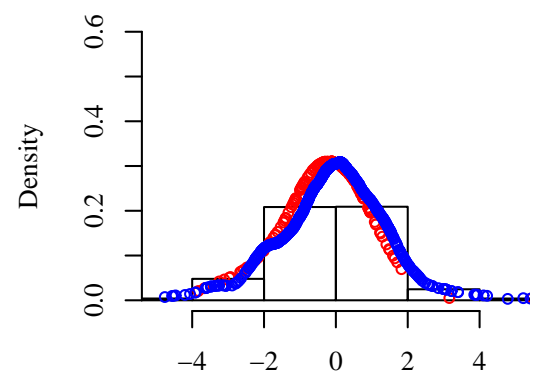

Change in log of wages

Manufacturing

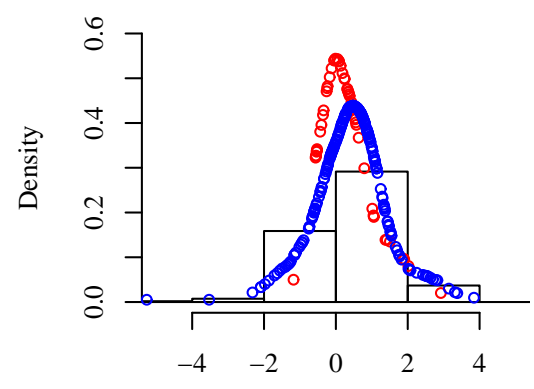

Change in log of wages

\section{Construction}

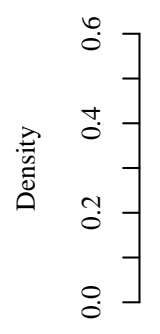

Change in log of wages

\section{Services}

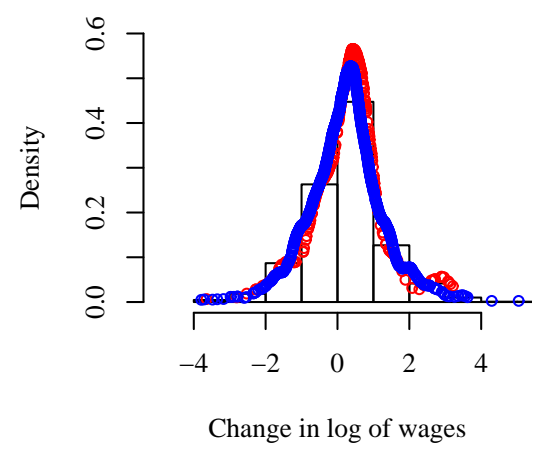

Source: IFLS.

Figure 3 shows the distribution of wage growth between 2000 and 2007 by employment sector. The histogram in the background describes the raw income growth data for the whole sector, while the overlaid curves in red (blue) show the non-parametric kernel density estimates for wage growth for individuals in earthquake (un)affected communities. The nonparametric density estimates are produced using the np package (Hayfield and Racine, 2008) and derived using a second order Epanechnikov as the kernel function; the smoothing parameter was selected via least squares crossvalidation as suggested by Rudemo (1982) and Bowman (1984) which minimizes the integrated squared error of the resulting estimate; the bandwidth is held fixed over the support of income growth. A visual inspection of the graphs suggests that they are in line with the theory if there are frictions in the local labor market: the earn- 
ings growth distribution of individuals employed in non-tradable sectors (construction and services) is shifted to the right for individuals who live in communities that were affected by earthquakes. Manufacturing and agriculture on the other hand, exhibit a shift to the left and therefore slow-down in income growth for earthquake affected communities.

We formally test the equality of the empirical probability density functions using a univariate entropy density equality test as proposed by Maasoumi and Racine (2002) with 99 bootstrap replications sampled from the pooled distribution. The test statistic and p-value as reported in Table 2 suggest that the null of equality can be rejected for the construction sector at the $10 \%$ level and for the agriculture and manufacturing sector at the $5 \%$ level. For services, on the other hand, we fail to reject the null of equality of the two probability density functions at the $10 \%$ level.

Table 2: Nonparametric Entropy Test for Univariate Density Equality (Maasoumi and Racine, 2002)

\begin{tabular}{lcc}
\hline \hline \multicolumn{1}{c}{ Sector } & Test Statistic & P-value \\
\hline Agriculture & 0.021 & 0.010 \\
Construction & 0.016 & 0.091 \\
Manufacturing & 0.061 & 0.010 \\
Services & 0.009 & 0.293 \\
\hline
\end{tabular}

Having established that earthquakes do appear to affect the distribution of earnings growth in the different sectors, we now examine in more detail the channels through which these effects might operate.

\section{Empirical Framework}

We attempt to identify the effect of destructive natural disasters from a number of angles: first, whether there is evidence for an expansion and contraction of certain sectors in the aftermath of an earthquake. Second, we test whether labor markets are sufficiently flexible to accommodate these demand shifts or whether are there long lasting sectoral wage premia even after occupational mobility has taken place; we finally explore whether natural disasters lead to pure location shifts of the income growth distribution or changes of the shape of the income growth distribution and discuss heterogeneity of impacts with regard to characteristics of the earthquake and the role of migration.

\subsection{Demand Effects}

We use the 9-year community level panel to explore whether we observe an expansion of employment in non-tradable sectors and a contraction in tradable sectors in communities that were affected by an earthquake. Further, we investigate the time structure of these sectoral shifts. The model to test whether there are demand effects 
is given by

$$
\text { Employment }_{j t}=\alpha+D_{E Q_{j s}}^{\prime} \beta+T_{t} \tau+P_{j}^{\prime} \gamma+\left(P_{j} * T_{t}\right)^{\prime} \rho+\left(\omega_{j}+\varepsilon_{j t}\right)
$$

for cluster $j=1, \ldots, J$ and $t=1, \ldots, T$ and $s=t-1, t, t+1, t+2, t+3 ;$ Employment $_{j t}$ measures the proportion of individuals employed in a particular sector in community $\mathrm{j}$ at time $\mathrm{t}$ and $D_{E Q_{j s}}$ is a $5 \times 1$ vector whose elements are equal to one for $t=s$. For example, if an earthquake occurred in 2005, then for the year 2004, $E Q_{j t-1}=1$, for $2005 E Q_{j t}=1$, in $2006 E Q_{j t+1}=1$, and so on. $P_{j}$ is a vector of province fixed effects to capture province level fixed effects in the various sectors. We also include a set of time dummies $T_{t}$ and interact these with the province dummies to allow for province specific time trends. The composite error term consists of $\omega_{j}$ which captures community level time invariant unobservable characteristics and $\varepsilon_{j t}$ which is assumed to be i.i.d. over time and across communities. Estimating equation 1 by OLS if $E\left[\omega_{j} \mid D_{E Q_{j s}}\right] \neq 0$ yields biased parameter estimates. Therefore, we transform the model by subtracting the mean of each variable which removes the community fixed effect $\omega_{j}$. This does not allow us to identify $\gamma$ anymore but $\beta$ and $\rho$ are still identified.

\subsection{Wage Effects}

In order to model how natural disasters impact on the conditional distribution of wages across certain sectors over time we would ideally estimate model 1 with wages as the dependent variable and earthquake-sector interaction terms as the conditioning variables. Unfortunately, the employment history does not collect information on the wages earned in each of the years, so that the only information on wages that is available is for the years in which the survey has been conducted. Therefore, we estimate variations of the following model

$$
\begin{aligned}
\Delta \ln W_{i j t} & =\alpha+X_{i j t}^{\prime} \beta+Z_{i j t}^{\prime} \gamma+\delta D_{E Q_{i j t}}+D_{S i j t}^{\prime} \phi+\lambda D_{E Q_{j t}^{C O M M}} \\
& +\left(D_{S i j t} * D_{E Q_{j t}^{C O M M}}\right)^{\prime} \theta+\Delta \varepsilon_{i j t}
\end{aligned}
$$

for individual $i=1, \ldots, N$, time $t=1, \ldots, T$ and cluster $j=1, \ldots, J ; W_{i j t}$ is $\log$ of hourly wages of individual $\mathrm{i}$ in cluster $\mathrm{j}$ at time t; $X_{i j t}$ is a vector of individual or household specific baseline characteristics (age, age squared, urban, primary, secondary, tertiary and adult education); $Z_{i j t}$ denotes a vector of occupation related dummy variables indicating the category of employment (self-employed, private worker, government worker and causal worker), firm size, its square, tenure in current job and union membership; $D_{E Q_{i j t}}$ is equal to 1 if a household reports to have been seriously affected by an earthquake in the last 5 years; $D_{\text {Sijt }}$ denotes a $4 \times 1$ vector of dummy variables for the sector in which the individual is employed in 2007 (agriculture, construction, manufacturing, services); $D_{E Q_{j t}^{C O M M}}$ is a dummy variable that is 
equal to 1 if a community experienced an earthquake in the last 5 years. Community fixed effects are included in some models, in which $\lambda$ is not identified anymore but the parameters on the interaction term $\theta$ are.

Wages are in first differences in order to remove the individual specific time invariant fixed effects. The individual level shock variable is included to account for individual heterogeneity due to idiosyncratic shocks to income growth (in order to disentangle the effect that operates through local labor markets as opposed to individual specific channels). Thus, $\lambda$ captures the impact of natural disasters on individual earnings growth through local labor markets; if $\lambda=0$ this indicates that local labor markets are flexible enough to accommodate these large shocks without significant losses in earnings growth. The parameter vector $\theta$ tests whether there is evidence for persistent wage premia in certain sectors. If labor markets are sufficiently flexible, and workers mobile, we would expect $\theta=0$ since workers would have responded to arising sectoral wage premia, shifted sectors and thereby driven premia towards zero.

\subsection{Quantile Regression}

While model 2 is informative on how the conditional expectation of earnings growth conditional on $X$ changes when communities are hit by a natural disaster, it does not contain information of how these effects vary along the conditional distribution. Therefore, this section employs quantile regression to allow for a richer characterization of the effect of natural disasters on earnings growth along the whole distribution of income growth. Instead of obtaining the parameter vectors of model 2 by minimizing the sum of squared residuals, parameters estimated by quantile regression for the $\tau$ th quantile are derived from an asymmetric loss function (Koenker and Bassett, 1978; Koenker, 2005)

$$
\min _{\beta \in \Re} \sum \rho_{\tau}\left(\Delta \ln W_{i j t}-\xi\left(X_{i}, \beta\right)\right)
$$

where $X_{i}$ is a matrix of all covariates included in equation $2, \beta$ is the coefficient vector and $\rho(u)$ is a piecewise linear function of the form

$$
\rho_{\tau}(u)=(\tau-1(u<0)) u .
$$

The function $\rho_{\tau}$ assigns different weights to residuals depending on whether the residual is positive or negative. For the special case in which $\tau=0.5$ this yields an estimate at the conditional median known as the conditional median estimator. Equation 3 is not continuously differentiable but the minimization problem can be solved by linear programming. As a consequence, gradient methods can not be used to derive the asymptotic distribution of the estimator. Standard errors are computed using a procedure proposed by Koenker and Bassett (1982). 


\section{Discussion}

This section discusses the results of the various empirical models outlined above, starting with evidence on employment effects. We then explore wage effects and present a number of robustness checks before characterizing these effects along the whole income growth distribution. Finally, we discuss heterogeneity with regard to the distance and magnitude of an earthquake and the role of migration in potentially biasing our results.

\subsection{Demand Effects}

Tables 3 - 6 present the results for specification 1 which tests whether there are significant shifts across employment sectors following an earthquake. As the random effects estimates are virtually identical in size and significance, we only report fixed effects estimates. Standard errors are corrected for correlation of errors for the same cluster across time, as well as for non-constant variances on the diagonal of the variance covariance matrix. The dependent variable is zero for clusters for which no individual in the survey works in a particular sector, and we have estimated the above specifications including both zero and positive observations. Limiting the sample to positive observations leaves the results virtually unchanged apart from slightly higher coefficients which would be expected in since the presence of zeros biases the estimates downwards. If the censoring would be due to a different data generating process for zero and non-zero observations this would require models such as a generalized tobit model that allow for either separate estimation or correlation between the errors of the two parts of the model. However, as here the presence of zeros is most likely due to sampling error, in the sense that no individuals working in a particular sector with positive wages were sampled in both rounds, this does not appear to be a major estimation issue.

The results suggest that there is a significant $2.7 \%$ point increase in the proportion of individuals employed in construction one year after the earthquake and a $5.9 \%$ point increase two years following the earthquake ${ }^{9}$. This effect is disappears again in the third year after the earthquake. As one would expect, there are no effects for the year prior to the earthquake as well as in the year the earthquake happens. The size and significance of the coefficients is remarkably robust to the inclusion of fixed effects, as well as to the joint inclusion of all the earthquake timing variables.

Table 4 illustrates that there is a matching contraction of the proportion of individuals working in the agricultural sector when a natural disaster hits a community. In a fairly symmetric manner, the proportion of individuals working in agriculture one year after an earthquake decreases by $4.1 \%$ points and $9.1 \%$ points two years after the

\footnotetext{
${ }^{9}$ We limited the sample to individuals who were residents in the same cluster in 2000 in order not to bias the estimate by in-migration of individuals into the IFLS households. If we use the whole sample regardless of where individuals resided in 2000, the effect for one year after the earthquake stays the same but for 2 years after the earthquake becomes insignificant.
} 
earthquake. There appears to be a shift back into the agriculture sector 3 years after an earthquake took place, but this effect is not robust to the inclusion of the whole set of time dummies in column (6) where similar to the construction sector, the effect vanishes in the third year after an earthquake took place. From this it appears that we observe a natural disasters push residents in a community from agriculture-based activities into the construction sector which is consistent with what the theoretical framework would predict at least for the agriculture and constructions sector. Having established that there are significant labor demand effects in earthquake affected communities, we now investigate whether labor markets are sufficiently flexible to accommodate these shifts.

\subsection{Wage Effects}

Table 7 presents the results of specification 2, which suggest that individuals' earnings bounce back after earthquakes as there is no evidence that the household-reported earthquake affects income growth after controlling for socio-economic variables, category of employment and occupational sector. Further, the coefficient on the community level earthquake shock is not significantly different from zero, indicating that there is no evidence that earthquakes impact on wage growth through local labor markets on average. However, when adding the sector-shock interaction terms, the coefficient on the community level earthquake shock becomes negative, although insignificant, suggesting that heterogeneity of impacts was upward biasing the coefficient towards zero in column (1). This bias stems from a significant and positive effect for individuals who live in a community that was affected by an earthquake, if they are employed in construction. Their wage growth was $60 \%$ higher compared to individuals employed in agriculture, while there is no effect for individuals employed in the manufacturing or service sector. The effect is robust to the inclusion of community fixed effects to account for community level heterogeneity such as differences in labor market integration and wage levels. This indicates that even after individuals have responded to to changes in local labor market conditions (which would drive down wage premia and thereby bias the estimate of $\theta$ towards zero), there are still significant and positive wage premia for individuals employed in construction.

\subsection{Robustness Checks}

This section reports the results of a number of robustness checks of specification 2, including different sets of controls, using USGS earthquake data as an alternative measure for the reported earthquake incidence, inclusion of other shock variables, province fixed effects, a trimmed sample and instrumenting for the earthquake variable using the USGS measure for earthquake incidence. As the coefficients do not change substantially when community fixed effects are included, and we would also like to inspect the stability of the coefficient on the community level earthquake shock (which 
is not identified anymore under the community fixed effects specification), we use column (3) of Table 7 as the base model which is reported in column (1) of Table 8.

If individuals' entrepreneurial talent changes over time and in response to an earthquake they enter the construction sector and start up firms there, then higher wage growth in the construction sector operates through unobserved changes in talent and shifts in employment categories rather than sectoral wage premia. Column (2) therefore drops the employment category variables which leaves the coefficient on the sector-shock interaction terms unaffected. Column (3) then adds the second most frequently reported natural disaster, floods, as an additional control to account for individual level heterogeneity in earnings. It is excluded in the base model due to concerns that floods are not exogenous as the location of a household which makes it more or less vulnerable to floods (i.e. next to rivers) is most likely correlated with other unobservable determinants of earnings growth. The results remain robust to its inclusion. Column (4) includes province fixed effects which also does not change the parameter estimates. Column (5) presents a trimmed sample which excludes the top and bottom one percentile of income growth which implies excluding 54 individuals. The size of the coefficient is stable when excluding outliers from the sample and increases in significance, with a significant effect now also for the services sector. Column (6) uses an alternative measure of earthquakes, from the US Geological Survey instead of the community level reported earthquake shock and column (7) uses the same measure on the trimmed sample used in column (5). As the measure constructed using data from the US Geological Survey is significantly more noisy than the reported earthquake measure from the IFLS questionnaire, standard errors on the coefficient of the sector-shock interaction terms are larger. However, when we use the trimmed sample in column (7) standard errors are smaller again. The coefficients are also fairly stable in size across the various specifications. Having established a robust and significant effect of earthquakes on wage growth in different sectors, we now explore whether these effects occur at certain parts of the income distribution or along the whole distribution by using quantile regression.

\subsection{Quantile Regression}

Table 9 shows the estimated quantile coefficients on the sector variables and the sector-shock interaction terms. Due to the symmetry of the distribution of the log of income growth, the coefficients for the 0.5 quantile, the median, are very similar to the conditional mean estimates. The results reveal that the positive sectoral wage premia in construction, manufacturing and services apparent from the least squares estimates are mainly driven by higher wage growth for individuals at the lower half of the income growth distribution. Further, the size of the coefficient on the earthquakesector interaction term tends to increase in size and significance at higher quantiles, a feature that OLS estimates do not reveal. Further, column (7) reveals that while the coefficient on the service sector-shock interaction term is never statistically sig- 
nificantly different from zero in the OLS estimates (apart from column (5) and (7) in Table 8 that use the trimmed sample), the quantile regression results show that there are significant and positive effects at the middle of the distribution and then again at the top also for the service sector. As quantile regression is less sensitive to outliers it allows us to recover this effect using the full sample; in the least squares regressions the significant effect for the service sector only appeared when we used the trimmed sample. This confirms that there are significant increases in wage growth for both sectors producing non-tradable goods, namely, the construction and the service sector, compared to tradable sectors such as agriculture (the base group) and manufacturing (for which there is no effect along the whole distribution).

Figure 9 graphically illustrates the results of the quantile regression over the whole income growth distribution. The x-axis marks the quantiles of the income growth distribution and the $y$-axis the size of the estimated coefficient with a reference line in cranberry at zero. The solid line shows the coefficient estimated by quantile regression with a $90 \%$ confidence band marked by the grey area. The dashed line represents the least squares estimate with a $90 \%$ confidence interval indicated by the dotted line. For both the employment category and the occupational sector, the quantile regression estimates lie outside the confidence interval of the least squares estimates, in particular at the high and low end of the distribution. Government workers and Casual workers appear to have had significantly higher income growth at the low levels of the income growth distribution compared to the self-employed.

Among individuals not living in an earthquake affected community, those at the lower half of the income growth distribution experienced higher growth when employed in construction, manufacturing or services compared to agriculture. On the other hand, for individuals who saw their income increase by more than the increase of the median, they experienced negative sectoral effects if employed in construction and manufacturing, where the quantile regression estimates are below the zero line and outside the least squares estimates. In other words, those who saw mild increases in income, still benefitted from being employed in any sector other than agriculture, while for those with large increases in income, there are negative returns to being employed in a non-agricultural sector. Interestingly, the bottom three panels show that earthquakes seem to neutralize the differential earnings growth patterns across sectors; the effect of being employed in the construction sector in an earthquake affected community is fairly constant along the income distribution, indicating that earthquakes exert a pure location shift rather than altering the shape of the conditional distribution. The graphs illustrate again that individuals employed in the services sector with wage growth between the 0.4 and 0.6 quantile experienced significantly higher wage growth if they were living in an earthquake affected community which is where the confidence band of the quantile regression does not include zero. For all three sector-shock interaction terms, the coefficients estimated by quantile regression lie within the confidence intervals for the least squares estimates over almost the 
whole range of the income growth distribution, suggesting that the interaction effects are fairly constant across the conditional distribution of the independent variable.

\subsection{Distance to the Epicenter and Magnitude}

Unfortunately the community questionnaire does not provide information on the magnitude of the earthquake and the distance to the epicenter. We have tried to backward construct these two variables by searching for earthquakes in the USGS database that happened in the year in which the community reported an earthquake within a radius of $90 \mathrm{~km}$. We then included the largest magnitude and smallest distance that was recorded for earthquakes in a particular year for a particular community. The coefficients on both variables are not significantly different from zero. Further, the other results remain unchanged, in both size and significance level of the coefficients, except that the coefficient on the earthquake-sector interaction term in table 8 is significant at the $11 \%$ level instead of the $10 \%$ level. Since it adds additional noise, and decreases the sample slightly as for some earthquakes the information on the year of the earthquake is missing, we decided to report the results without these additional controls.

\subsection{Migration}

One concern is that natural disasters lead to large flows of migration. It could be that those with intact safety nets manage to stay in a community, and those without are forced to migrate. On the other hand, it might be that migrating households are those who are less liquidity constrained or have better connections in other locations. Therefore, it is not clear in which direction the bias goes. In the migration section of the questionnaire the three most frequently stated reasons for migration are work-related migration (34\%), marriage (15\%) and education (11\%); only $0.33 \%$ of individuals give natural disasters as a reason for migration. However, while providing some evidence, one would worry that natural disasters nevertheless play an important role in affecting an individual's migration decision but the ultimate reason given will still be to find work or be closer to the family. For example, for an individual in an area that has frequently been hit by an earthquake or a flood, an individual migrating might still give work as the reason for migration although clearly the lack of work in the home location is not uncorrelated with the event of a natural disaster. Therefore, we explore whether there is any significant link in the data between migration and the event of an earthquake. We construct a number of variables to measure migration flows: the proportion of a household who migrated between 2000 and 2007, the number of household members who migrated between 2000 and 2007, and the change in the number of migrants in a household between 1997 and 2000, and 2000 and 2007. Regressing these migration measures on the earthquake variable, controlling for province fixed effects and urban/rural location, a linear model, an ordered probit 
and a probit model do not show any evidence for a significant relationship between the propensity to migrate and the event of an earthquake. Therefore, the local economy appears to be fairly insulated and the population remaining after an earthquake representative.

\section{Conclusion and Next Steps}

This paper studies how local labor markets adjust to destructive natural disasters, in particular the change in the relative price of tradable to non-tradable goods induced by the increase in the demand for construction as well as the inflow of resources in the aftermath of natural disasters. To our knowledge, this is the first study that explores the impact of destructive natural disasters on local labor markets in the context of a low or low to middle income country.

Our results are in line with the predictions coming out of the theoretical framework and suggest that there are important general equilibrium effects, such as a reallocation of employment and wage premia between sectors producing tradable vs non-tradable goods. First, using a community-level panel we establish that there are significant shifts in the demand for labor from the agriculture sector into the construction sector in the two years following an earthquake. Second, we find that individuals employed in non-tradable sectors in earthquake affected communities experience significant and positive wage premia which persist even after mobility has taken place, suggesting that local labor markets exhibit a fairly high degree of rigidity. These effects are homogenous along the quantiles of the conditional income growth distribution. Thereby, they neutralize otherwise arising differential earnings growth patterns across sectors and operate as pure location shifts of the income distribution than altering the shape. As a next step we want to further investigate the channels through which these persistent wage effects occur, in particular infrastructure destruction and changes in the relative prices of goods. 


\section{References}

Baez, J., and I. Santos (2008): "On Shaky Ground: The Effects of Earthquakes on Household Income and Poverty," .

BanerJee, L. (2007): "Effect of Flood on Agricultural Wages in Bangladesh: An Empirical Analysis," World Development, 35(11), 1989-2009.

BAPPENAS (2006): "Preliminary Damage and Loss Assessment: Yogyakarta and Central Java Natural Disaster," .

Belasen, A. R., and S. Polachek (2009): "How Disasters Affect Local Labor Markets: The Effects of Hurricanes in Florida," Journal of Human Resources, 44(1), 251.

Belasen, A. R., and S. W. Polachek (2008): "How Hurricanes Affect Wages and Employment in Local Labor Markets," American Economic Review, 98(2), 49-53.

Benson, C., and E. Clay (2004): Understanding the economic and financial impacts of natural disasters. World Bank Publications.

BNPB ET AL (2009): "West Sumatra and Jambi Natural Disasters: Damage, Loss and Preliminary Needs Assessment," Joint report by the BNPB, Bappenas, and the Provincial and District/City Governments of West Sumatra and Jambi and international partners.

Bowman, A. (1984): "An alternative method of cross-validation for the smoothing of density estimates," Biometrika, 71(2), 353.

Cameron, L., and C. Worswick (2003): "The labor market as a smoothing device: labor supply responses to crop loss," Review of Development Economics, 7(2), 327341.

CARrington, W. (1996): "The Alaskan labor market during the pipeline era," Journal of Political Economy, 104(1), 186-218.

Cavallo, E., And I. Noy (2009): "The Economics of Natural Disasters - A Survey," Working Papers 200919, University of Hawaii at Manoa, Department of Economics.

Collier, P., And J. Gunning (1999): Trade Shocks in Developing Countries: Africa. Oxford University Press, USA.

Corden, W. (1984): "Booming sector and Dutch disease economics: survey and consolidation," Oxford Economic Papers, 36(3), 359-380.

Corden, W., and P. Neary (1982): "Booming Sector and De-Industrialization in a Small Open Economy," Economic Journal, 92, 368. 
Cuaresma, C., Hlouskova, and Obersteiner (2008): "Natural Disasters As Creative Destruction? Evidence From Developing Countries," Economic Inquiry, 46(2), 214-226.

Datt, G., and H. Hoogeveen (2003): "El Nino or El Peso? Crisis, poverty and income distribution in the Philippines," World Development, 31(7), 1103-1124.

Dercon, S. (2004): "Growth and shocks: evidence from rural Ethiopia," Journal of Development Economics, 74(2), 309-329.

Government of Haiti et AL (2010): "Haiti Earthquake PDNA: Assessment of damage, losses, general and sectoral needs, Annex to the Action Plan for National Recovery and Development of Haiti," Working paper prepared by the Government of Haiti with support from the International Community.

Halliday, T. (2006): "Migration, Risk, and Liquidity Constraints in El Salvador," Economic Development and Cultural Change, 54(4), 893-925.

Hayfield, T., and J. S. Racine (2008): "Nonparametric Econometrics: The np Package," Journal of Statistical Software, 27(5), 1-32.

Hochrainer, S. (2009): "Assessing The Macroeconomic Impacts Of Natural Disasters," Policy Research Working Paper 4968, World Bank.

Jayachandran, S. (2006): "Selling Labor Low: Wage Responses to Productivity Shocks in Developing Countries," Journal of Political Economy, 114(3), 538-575.

Keane, M., and E. Prasad (1996): "The employment and wage effects of oil price changes: a sectoral analysis," The Review of Economics and Statistics, 78(3), 389400 .

KLine, P. (2008): "Understanding Sectoral Labor Market Dynamics: An Equilibrium Analysis of the Oil and Gas Field Services Industry," .

Kochar, A. (1999): "Smoothing consumption by smoothing income: hours-of-work responses to idiosyncratic agricultural shocks in rural India," Review of Economics and Statistics, 81(1), 50-61.

Koenker, R. (2005): Quantile regression. Cambridge University Press.

Koenker, R., and J. Bassett, Gilbert (1978): "Regression Quantiles," Econometrica, 46(1), 33-50.

Koenker, R., and J. Bassett, Gilbert (1982): "Robust Tests for Heteroscedasticity Based on Regression Quantiles," Econometrica, 50(1), 43-61.

Loayza, N., E. Olaberría, J. Rigolini, and L. Christiaensen (2009): "Natural Disasters and Growth," Discussion paper. 
MaAsoumi, E., And J. RAcine (2002): "Entropy and predictability of stock market returns," Journal of Econometrics, 107(1-2), 291-312.

McIntosh, M. F. (2008): "Measuring the Labor Market Impacts of Hurricane Katrina Migration: Evidence from Houston, Texas," American Economic Review, $98(2), 54-57$.

MoretTi, E. (2010a): "Local Labor Markets," Handbook of Labor Economics, forthcoming.

(2010b): "Local Multipliers," American Economic Review, 100(2), 373-77.

Mueller, V., And D. Osgood (2009): "Long-term Impacts of Droughts on Labour Markets in Developing Countries: Evidence from Brazil," Journal of Development Studies, 45(10), 1651-1662.

Mueller, V., And A. Quisumbing (2010): "Short- and long-term effects of the 1998 Bangladesh flood on rural wages," Discussion paper.

Noy, I. (2009): "The macroeconomic consequences of disasters," Journal of Development Economics, 88(2), 221-231.

Paxson, C. H. (1992): "Using Weather Variability to Estimate the Response of Savings to Transitory Income in Thailand," American Economic Review, 82(1), $15-33$.

Premand, P. (2008): "Hurricane Mitch and consumption growth of Nicaraguan agricultural households," The Centre for the Study of African Economies Working Paper.

Rose, E. (2001): "Ex ante and ex post labor supply response to risk in a low-income area," Journal of Development Economics, 64(2), 371-388.

Rudemo, M. (1982): "Empirical choice of histograms and kernel density estimators," Scandinavian Journal of Statistics, 9(2), 65-78.

Silva, D. G. D., R. P. McComb, Y.-K. Moh, A. R. Schiller, and A. J. Vargas (2010): "The Effect of Migration on Wages: Evidence from a Natural Experiment," American Economic Review, 100(2), 321-26.

Skidmore, M., and H. Toya (2002): "Do natural disasters promote long-run growth?," Economic Inquiry, 40(4), 664-687.

Strauss, J., K. Beegle, A. Dwiyanto, Y. Herawati, D. Pattinasarany, E. Satriawan, B. Sikoki, B. Sukamdi, and F. Witoelar (2004): Indonesian living standards three years after the crisis: evidence from the Indonesia Family Life Survey. RAND Corporation. 
Strobl, E. (2010): "The economic growth impact of hurricanes: evidence from US coastal counties," The Review of Economics and Statistics,forthcoming.

StromberG, D. (2007): "Natural Disasters, Economic Development, and Humanitarian Aid," Journal of Economic Perspectives, 21(3), 199-222.

Takasaki, Y., B. L. Barham, and O. T. Coomes (2010): "Smoothing Income against Crop Flood Losses in Amazonia: Rain Forest or Rivers as a Safety Net?," Review of Development Economics, 14(1), 48-63.

Thomas, D., K. Frankenberg, E.and Beegle, and G. Teruel (1999): "Household budgets, household composition and the crisis in Indonesia: evidence from longitudinal household survey data," Mimeo.

Townsend, R. M. (1994): "Risk and Insurance in Village India," Econometrica, 62(3), 539-91.

Udry, C. (1995): "Risk and Saving in Northern Nigeria," American Economic Review, 85(5), 1287-1300.

US Geological Survey (2008): "Seismic Hazard of Western Indonesia," National Earthquake Information Center.

VAn Den Berg, M. (2010): "Household income strategies and natural disasters: Dynamic livelihoods in rural Nicaragua," Ecological Economics, 69(3), 592-602.

Vincenty, T. (1975): "Direct and inverse solutions of geodesics on the ellipsoid with application of nested equations," Survey review, 23(176), 88-93.

World BANK (2008): "Aceh Tsunami Reconstruction Expenditure Tracking Update," .

YANG, D. (2008): "Risk, Migration, and Rural Financial Markets: Evidence from Earthquakes in El Salvador," Social Research: An International Quarterly, 75(3), 955-992. 


\section{Appendix}

Table 3: Demand effects; dependent variable: proportion of individuals employed in the construction sector in a cluster

\begin{tabular}{lcccccc} 
& FE1 & FE2 & FE3 & FE4 & FE5 & FE6 \\
\cline { 2 - 7 } & $(1)$ & $(2)$ & $(3)$ & $(4)$ & $(5)$ & $(6)$ \\
\hline Year before earthquake & 0.0007 & & & & & 0.006 \\
Year of earthquake & $(0.003)$ & & & & & $0.004)$ \\
& & -.004 & & & & 0.006 \\
One year after earthquake & & $(0.009)$ & & & & $0.008)$ \\
& & & 0.027 & & & $(0.032)^{* *}$ \\
Two years after earthquake & & & $(0.013)^{* *}$ & & & 0.059 \\
& & & & $(0.032)^{*}$ & & $(0.032)^{* *}$ \\
Three years after earthquake & & & & & -.005 & 0.009 \\
& & & & & $(0.005)$ & $(0.007)$ \\
Obs. & 2751 & 2751 & 2751 & 2751 & 2751 & 2751 \\
$R^{2}$ & 0.053 & 0.053 & 0.058 & 0.058 & 0.053 & 0.065 \\
\hline
\end{tabular}

Notes: all models include community fixed effects, a dummy for each of the time periods and province fixed effects interacted with time dummies; robust standard errors in parentheses; ${ }^{*},{ }^{* *},{ }^{* * *}$ denote significance at $10 \%, 5 \%$ and $1 \%$ levels.

Table 4: Demand effects; dependent variable: proportion of individuals employed in the agricultural sector in a cluster

\begin{tabular}{|c|c|c|c|c|c|c|}
\hline & FE1 & FE2 & FE3 & FE4 & FE5 & FE6 \\
\hline & (1) & $(2)$ & $(3)$ & (4) & $(5)$ & $(6)$ \\
\hline Year before earthquake & $\begin{array}{c}0.004 \\
(0.004)\end{array}$ & & & & & $\begin{array}{l}-. .004 \\
(0.007)\end{array}$ \\
\hline Year of earthquake & & $\begin{array}{c}0.005 \\
(0.008)\end{array}$ & & & & $\begin{array}{l}-.008 \\
(0.013)\end{array}$ \\
\hline One year after earthquake & & & $\begin{array}{l}-.041 \\
(0.025)\end{array}$ & & & $\begin{array}{c}-.047 \\
(0.029)^{*}\end{array}$ \\
\hline Two years after earthquake & & & & $\begin{array}{c}-.091 \\
(0.052)^{*}\end{array}$ & & $\begin{array}{c}-.098 \\
(0.054)^{*}\end{array}$ \\
\hline Three years after earthquake & & & & & $\begin{array}{c}0.03 \\
(0.011)^{* * *}\end{array}$ & $\begin{array}{c}0.01 \\
(0.015)\end{array}$ \\
\hline $\begin{array}{l}\text { Obs. } \\
R^{2}\end{array}$ & $\begin{array}{c}2751 \\
0136\end{array}$ & $\begin{array}{c}2751 \\
0.136\end{array}$ & $\begin{array}{l}2751 \\
0.141\end{array}$ & $\begin{array}{l}2751 \\
0.142\end{array}$ & $\begin{array}{l}2751 \\
0.136\end{array}$ & $\begin{array}{l}2751 \\
0.148\end{array}$ \\
\hline
\end{tabular}

Notes: all models include community fixed effects, a dummy for each of the time periods and province fixed effects interacted with time dummies; robust standard errors in parentheses; ${ }^{*},{ }^{* *},{ }^{* * *}$ denote significance at $10 \%, 5 \%$ and $1 \%$ levels. 
Table 5: Demand effects; dependent variable: proportion of individuals employed in the manufacturing sector in a cluster

\begin{tabular}{lcccccc} 
& FE1 & FE2 & FE3 & FE4 & FE5 & FE6 \\
\cline { 2 - 6 } & $(1)$ & $(2)$ & $(3)$ & $(4)$ & $(5)$ & $(6)$ \\
\hline Year before earthquake & 0.0009 & & & & & 0.007 \\
Year of earthquake & $(0.004)$ & & & & & $(0.008)$ \\
& & 0.005 & & & & 0.014 \\
One year after earthquake & & $(0.008)$ & & & & $0.013)$ \\
& & & 0.025 & & & 0.031 \\
Two years after earthquake & & & $(0.019)$ & & & $-.023)$ \\
& & & & $(0.017$ & & $(0.015)$ \\
Three years after earthquake & & & & & -.008 & -.002 \\
Obs. & 2751 & 2751 & 2751 & 2751 & 2751 & 2751 \\
$R^{2}$ & 0.066 & 0.066 & 0.068 & 0.066 & 0.066 & 0.069 \\
\hline
\end{tabular}

Notes: all models include community fixed effects, a dummy for each of the time periods and province fixed effects interacted with time dummies; robust standard errors in parentheses; ${ }^{*},{ }^{* *},{ }^{* * *}$ denote significance at $10 \%, 5 \%$ and $1 \%$ levels.

Table 6: Demand effects; dependent variable: proportion of individuals employed in the services sector in a cluster

\begin{tabular}{|c|c|c|c|c|c|c|}
\hline 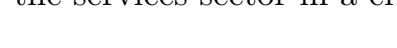 & FE1 & FE2 & FE3 & $\mathrm{FE} 4$ & FE5 & FE6 \\
\hline & $(1)$ & $(2)$ & $(3)$ & $(4)$ & $(5)$ & $(6)$ \\
\hline Year before earthquake & $\begin{array}{l}-.006 \\
(0.005)\end{array}$ & & & & & $\begin{array}{c}-.009 \\
(0.008)\end{array}$ \\
\hline Year of earthquake & & $\begin{array}{c}-.006 \\
(0.008)\end{array}$ & & & & $\begin{array}{l}-.011 \\
(0.012)\end{array}$ \\
\hline One year after earthquake & & & $\begin{array}{c}-.011 \\
(0.017)\end{array}$ & & & $\begin{array}{c}-.015 \\
(0.021)\end{array}$ \\
\hline Two years after earthquake & & & & $\begin{array}{c}0.05 \\
(0.033)\end{array}$ & & $\begin{array}{c}0.045 \\
(0.034)\end{array}$ \\
\hline Three years after earthquake & & & & & $\begin{array}{c}-.018 \\
(0.015)\end{array}$ & $\begin{array}{c}-.017 \\
(0.017)\end{array}$ \\
\hline $\begin{array}{l}\text { Obs. } \\
R^{2}\end{array}$ & $\begin{array}{c}2751 \\
0.183\end{array}$ & $\begin{array}{c}2751 \\
0.183\end{array}$ & $\begin{array}{l}2751 \\
0.183\end{array}$ & $\begin{array}{c}2751 \\
0.184\end{array}$ & $\begin{array}{c}2751 \\
0.183\end{array}$ & $\begin{array}{c}2751 \\
0.184\end{array}$ \\
\hline
\end{tabular}

Notes: all models include community fixed effects, a dummy for each of the time periods and province fixed effects interacted with time dummies; robust standard errors in parentheses; ${ }^{*},{ }^{* *},{ }^{* * *}$ denote significance at $10 \%, 5 \%$ and $1 \%$ levels. 
Table 7: Wage effects; dependent variable: change in log of hourly wage

\begin{tabular}{lcccc} 
& EQ1 & FE1 & EQ2 & FE2 \\
\cline { 2 - 5 } & $(1)$ & $(2)$ & $(3)$ & $(4)$ \\
\hline Earthquake & -.021 & -.161 & -.067 & -.145 \\
Wage Worker & $(0.134)$ & $(0.232)$ & $(0.14)$ & $(0.23)$ \\
& 0.168 & 0.166 & 0.164 & 0.167 \\
Government Worker & $(0.079)^{* *}$ & $(0.099)^{*}$ & $(0.079)^{* *}$ & $(0.098)^{*}$ \\
& -.012 & 0.015 & -.010 & 0.015 \\
Casual Worker & $(0.063)$ & $(0.072)$ & $(0.063)$ & $(0.073)$ \\
& -.040 & -.010 & -.051 & -.026 \\
Construction & $(0.08)$ & $(0.091)$ & $(0.08)$ & $(0.092)$ \\
& 0.244 & 0.279 & 0.144 & 0.166 \\
Manufacturing & $(0.087)^{* * *}$ & $(0.109)^{* *}$ & $(0.097)$ & $(0.116)$ \\
& 0.445 & 0.521 & 0.351 & 0.411 \\
Services & $(0.111)^{* * *}$ & $(0.132)^{* * *}$ & $(0.113)^{* * *}$ & $(0.131)^{* * *}$ \\
& 0.24 & 0.309 & 0.195 & 0.249 \\
Earthquake Community & $(0.077)^{* * *}$ & $(0.098)^{* * *}$ & $(0.089)^{* *}$ & $(0.108)^{* *}$ \\
& 0.03 & & -.208 & \\
Earthquake*Construction & $(0.071)$ & & $(0.161)$ & \\
& & & 0.476 & 0.532 \\
Earthquake*Manufacturing & & & $(0.21)^{* *}$ & $(0.272)^{*}$ \\
& & & 0.483 & 0.547 \\
Earthquake*Services & & & $(0.326)$ & $(0.396)$ \\
& & & 0.242 & 0.278 \\
Obs. & & & $(0.161)$ & $(0.23)$ \\
$R^{2}$ & 2770 & 2770 & 2770 & 2770 \\
\hline
\end{tabular}

Notes: all models include controls for age, age squared, urban, primary, secondary, tertiary and adult education, firm size, firm size squared, tenure, union membership; omitted employment category and sector are self-employed and agriculture, respectively; (2) and (4) include community fixed effects; robust standard errors in parentheses, clustered at the community level; ${ }^{*},{ }^{* *},{ }^{* * *}$ denote significance at $10 \%, 5 \%$ and $1 \%$ levels. 


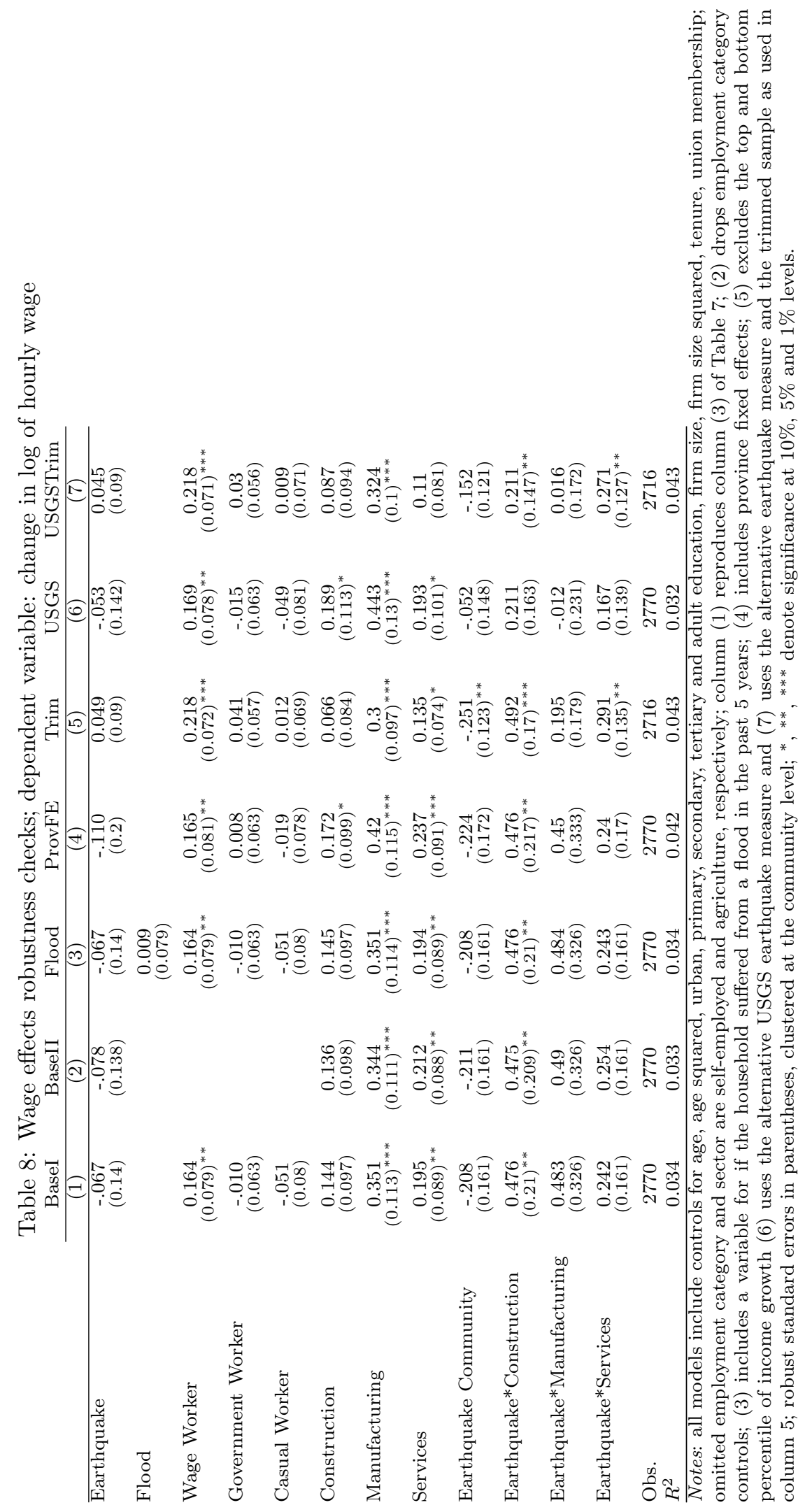




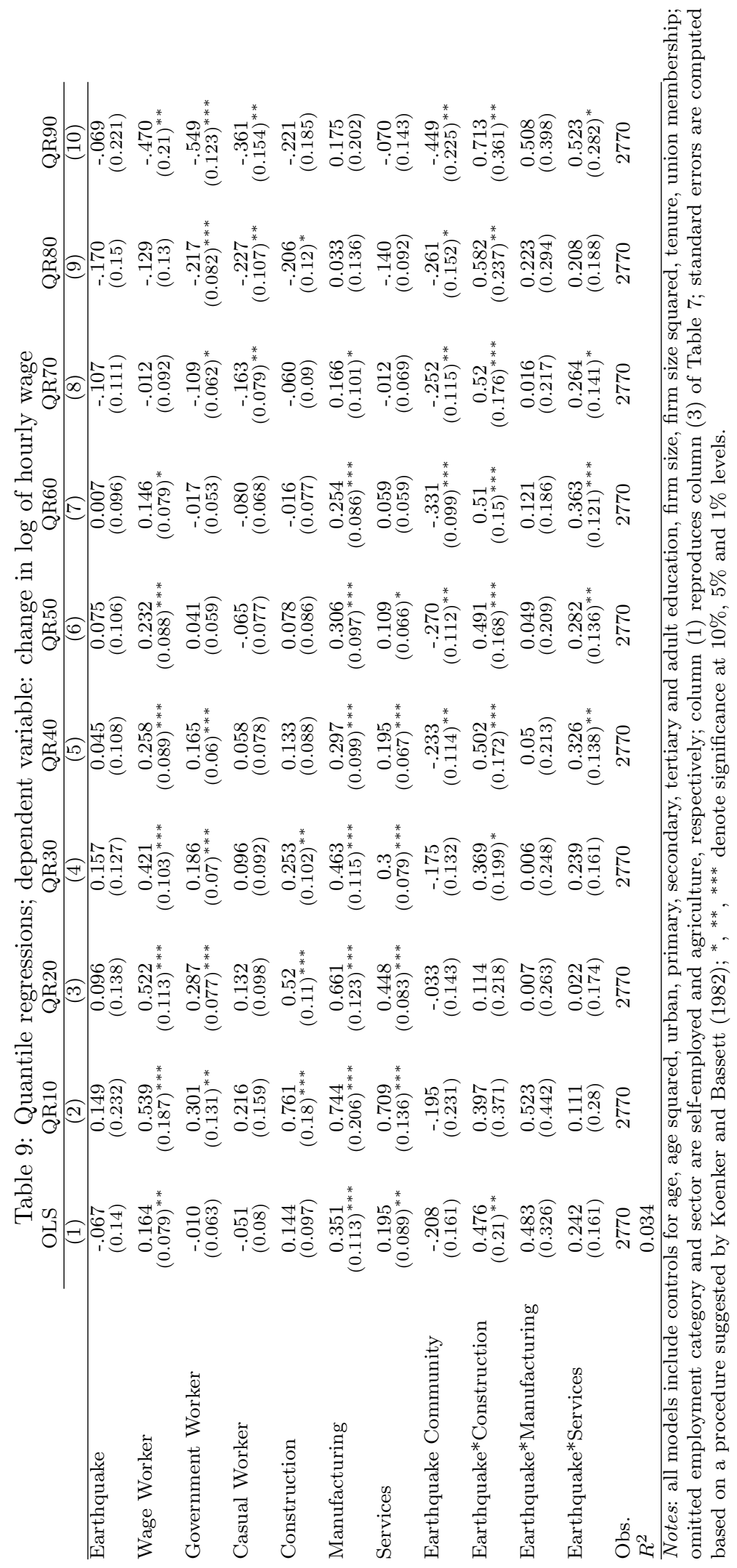


Figure 4: Quantile regression and OLS coefficients and confidence intervals for each regressor as q varies from 0 to 1
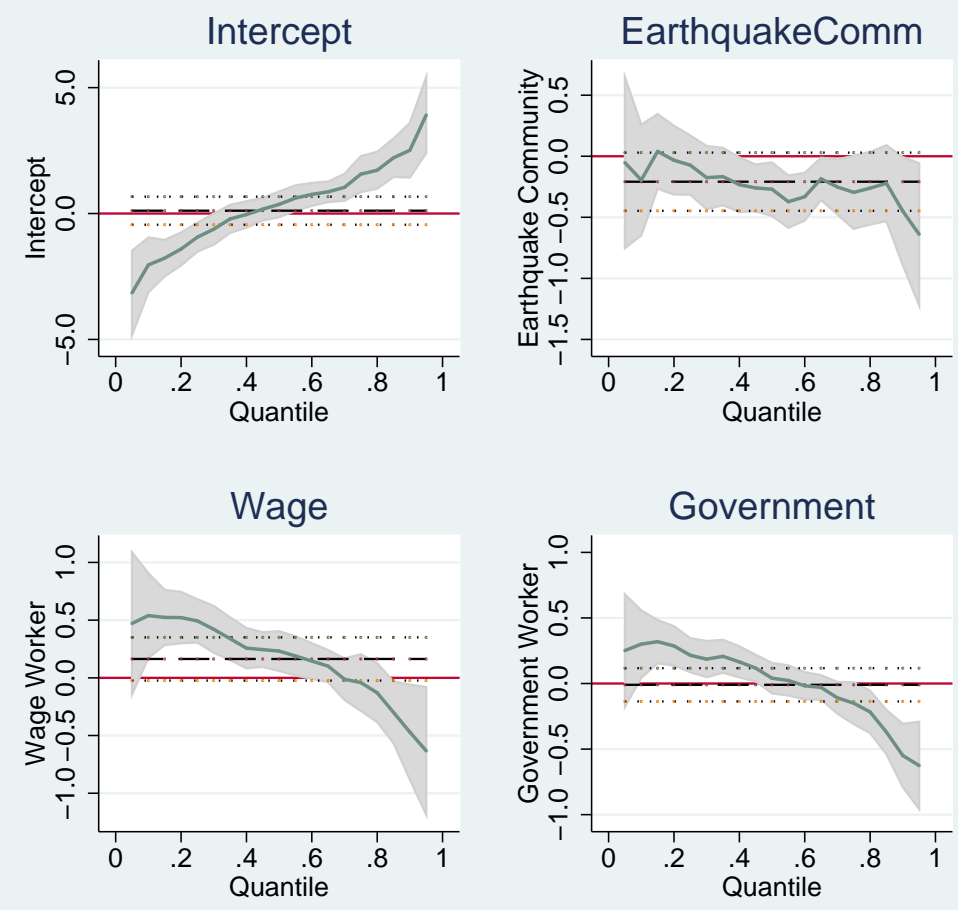

Casual
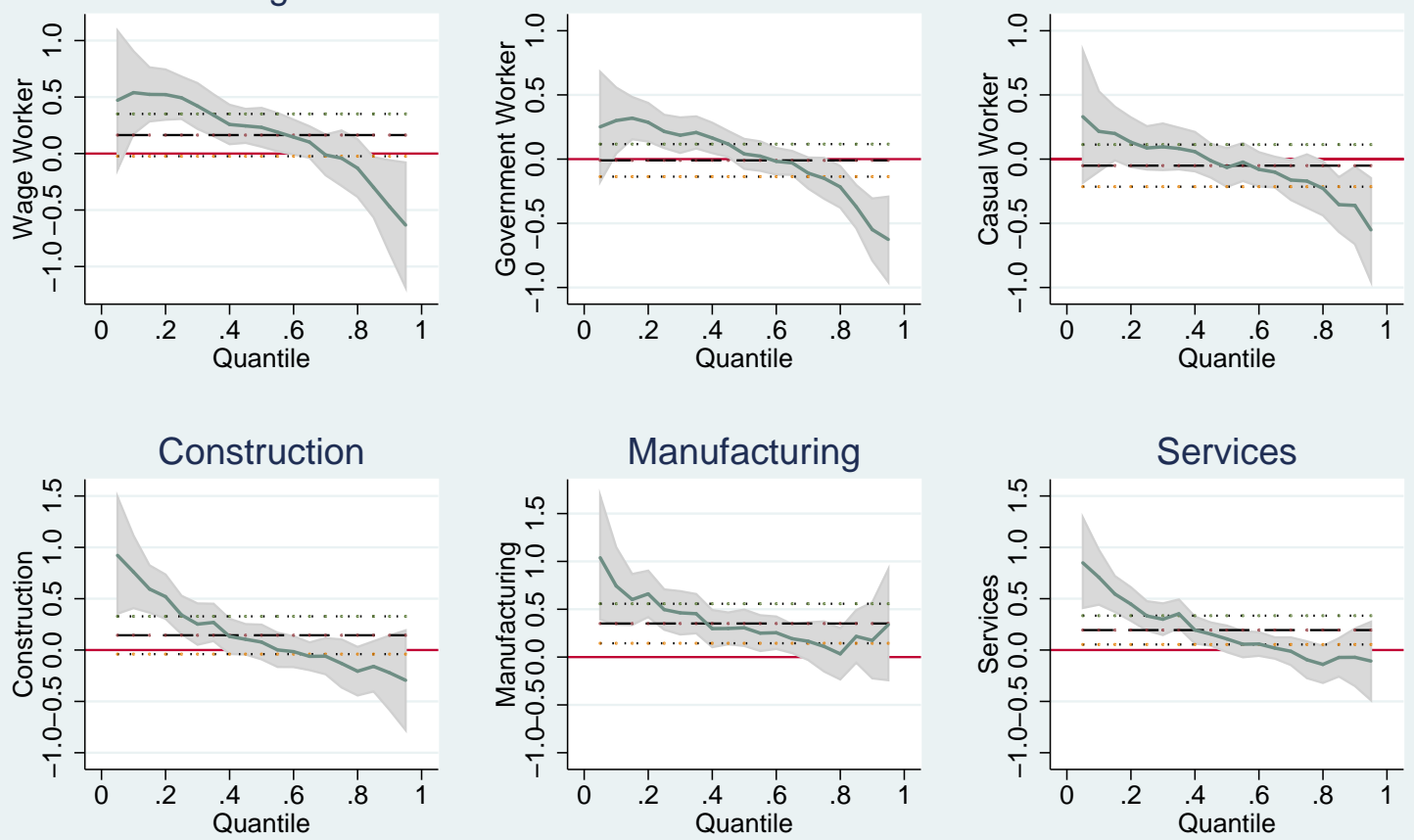

Services

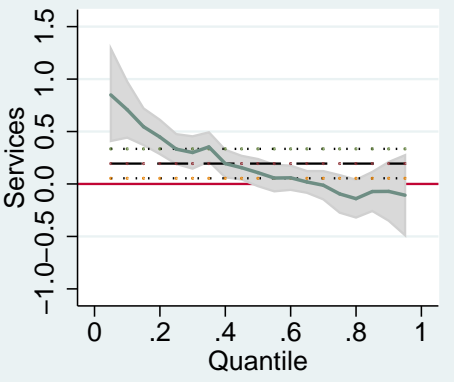

Earthquake*Construction
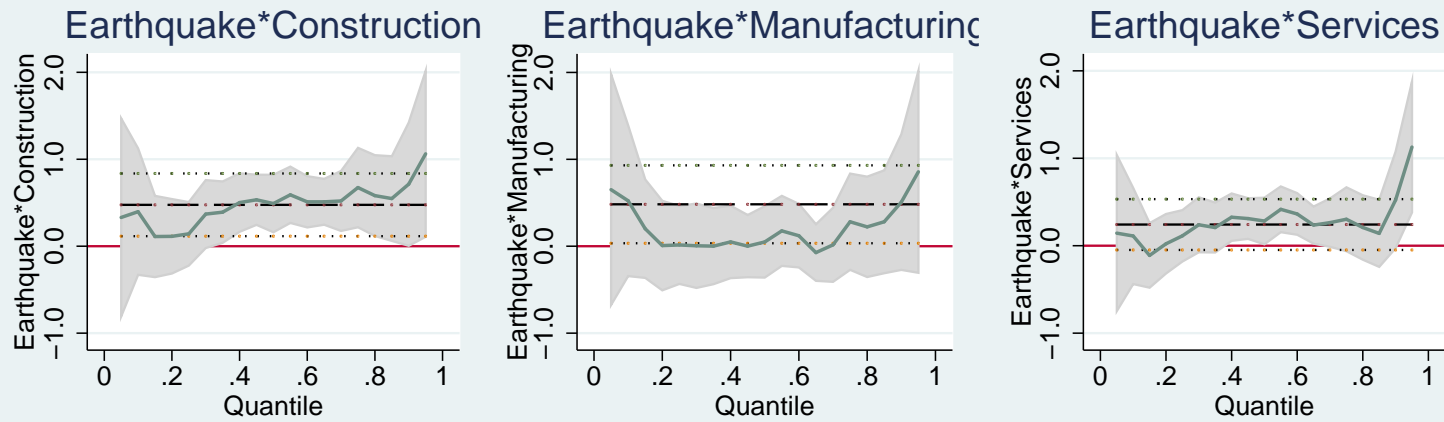

Notes: the $\mathrm{x}$-axis marks the quantiles of the income growth distribution and the $\mathrm{y}$-axis the size of the estimated coefficient with a reference line in cranberry at zero; the solid green shows the coefficient estimated by quantile regression over the income growth distribution with a $90 \%$ confidence band marked by the grey area; the dashed line represent $\$$ the least squares estimate with a $90 \%$ confidence interval indicated by the dotted line. 